\title{
A Review of Studies on Sports Literatures of the Tang Dynasty
}

\author{
Junli $\mathrm{Yu}$ \\ Department of Sports Media and Cultural Studies \\ Xi'an Physical Education University \\ Xi'an 710068,China \\ e-mail: rainlyer@126.com
}

\begin{abstract}
This article adopts the methods of literature consultation, expert interview, induction,deduction and logical analysis to review the existing research findings of sports literature of the Tang Dynasty based on both relevant publications of predecessors and modern scholars and research papers in the past three decades. The results indicates that the researchers have been breaking new ground and making great achievement in terms of study on sports literature of the Tang Dynasty for decades. However, the current research status reveals various deficiencies, of which the concrete manifestations include the following three points:1) Imbalance of research effort: People pay much more attention to poetry than to prose (ode);2) Lots of superficial researches and repetitive researches presented few original views. It should be particularly noted that excessive attention has been given to some certain sports poems; as a result, the subjects of study were extremely simplex, concentrated or even repeated;3) Monotonous research techniques lead to obviously inadequate integral and systematic study.
\end{abstract}

\section{Keywords-Sports;literature; the Tang Dynasty}

\section{INTRODUCTION}

The high-spirited magnificent culture of the Tang Dynasty delivers extensive knowledge and profound scholarship, while sports culture and literary achievements are particularly considered as two insurmountable "peaks" in the history of Chinese ancient culture. As an excellent combination of the two "peaks", sports literature expanded the creation sight of Tang literature, having developed a unique culture and art landscape. However, the study of sports literature of the Tang Dynasty has for long been given inadequate attention. With the continuous expansion and promotion of traditional culture research horizon in recent years, sports literature of the Tang Dynasty as an interdisciplinary literary form has begun to attract the attention of researchers from the world of sports. Papers on this theme have been reported now and then especially since the 1980s. The paper will sort out the existing research findings from the relevant publications of predecessors and modern scholars and the research papers published in recent 30 years so as to identify the focuses of present study and forecast the research prospects.

\section{COMPILATION OVERVIEW OF SPORTS LITERATURE OF THE TANG DYNASTY}

The concept of "sports" was not given birth in the Tang
Dynasty.It was imported from the West in the Westernization Movement launched by the Qing Regime in the 1880s, and accordingly, Tang Literature covered no sports issues in history. Although relevant works were not clearly classified from a sports point of view separately, lots of specific events such as competitive games \& entertainment, health exercises and military martial arts were widely carried out in the Tang Dynasty. Monographs of the Tang Dynasty and later periods on Tang poetry and prose closely related with sports issues were usually included in the category of acrobatics gymnastics, gambling, skill and the like.

Since ancient times, there have been scholars giving their attention to sports poetry of the Tang Dynasty. The Classified Collection of Tang's Poems by Zhang Zhixiang in the Ming Dynasty is the most representative study on classification of Tang poetry in the history, where Vol. 188 is the section of acrobatics gymnastics ${ }^{[1]}$, including 42 poems directly related to sports, and covering a number of sports activities such as archery, board game, kite flying, ball game, swing, boat race, pole climbing, tug of war and rope walking. Besides, the Outstanding Flowers of Literary Garden compiled by Li Fang et al in the Song Dynasty also includes sports poetry of the Tang Dynasty. Vol. 348 of poems describe such sports activities as gambling, miscellaneous songs, board game, ball game and boat race and covers such masterpieces describing sports activities as A Song of Reward for Han Yu the Official Collator Playing Ball Game by Zhang Jianfeng, the Song of Boat Race by Liu Yuxi and the Xiliang Tricks by Bai Juyi.

With respect to sports literature of the Tang Dynasty, existing modern research works mainly include the Classified Collection of Chinese Poetry by Jian Ye et al and the Collection of Classified Appreciation Reviews on the Complete Tang Poems by Pan Baiqi etc. . The Classified Collection of Chinese Poetry and Prose classified the sports activities described in Tang poetry into leisurely activity, seasonal activity, art activity and folk activity. A section that specially describes the Chang'an Skills in Tang poetry in the Tang Poetry and Chang'an by Yan Qi covers board game, kite flying, swing, kick-ball game, ball-game playing and tug-of-war etc. [2]. This book gives a description of abundant sports activities in Tang poetry, but the author allocated the variety of sports activities of the Tang Dynasty to other cultural activities without performing the classification separately from a sports point of view. . It is 
worth noting that the Collection of Classified Appreciation Reviews on the Complete Tang Poems by Pan Baiqi classified the Complete Tang Poems - the scale of the most ambitious collection of Tang poetry by subject content, where Section 48 focuses on sports activities. This publication is among the earliest works that clearly put forward the concept of sports poetry of the Tang Dynasty in China. However, this book includes limited number of works and provides only simple classification, failing to reveal the overall scene of sports activities in Tang poetry in a comprehensive and centralized manner. Since the 1990s, a number of collections of ancient sports poems have been published, such as Chinese ancient sports Anthologyby Li Ruke, Chinese ancient sports Anthologyby Lu Jinhua and Jin Lei, all of which are concerned about sports poetry of the Tang Dynasty. In particular, the Highlights of Chinese Classical Sports Literatures [3] by Li Guohua gives a lot of words to sports poetry of the Tang Dynasty. Poetry related to Dance \& acrobatics is receiving special attention in academia today. The Materials of Music and Dance in the Complete Tang Poems and the Selective Comments on Tang Poetry relevant to Music, Dance and Acrobatics by $\mathrm{Fu}$ Zhenggu are centralized collections of Tang poetry of this kind.

The Outstanding Flowers of Literary Garden and the Complete Tang Prosesare among the key classic general collections of Tang literary works. . The Outstanding Flowers of Literary Garden by Lifang et al of Song Dynasty divides literary works of Tang Dynasty into 39 categories including ode, poem and essay etc.; odes are further classified into acrobatics, archery and board game etc. There are lots of excellent Tang odes describing sports activities. Vol. 81 and 82 collect the ode of acrobatics, including the Ode of Tug-of-war by Xue Sheng, the Ode of Emperor HanWu's Swinging in Backyard by Gao Wuji, the Ode of Female Dancer's Demonstrating Her Riding Skill by Li Zhuo, the Ode of Watching Horse Dance at the Building of Diligence in Qianqiu Festival by Qianqi, the Ode of Female Dancers' Balance on Ball by Wang Yong, the Ode of Sword Dance by General Pei by Qiao Tan and other famous masterpieces of sports ode. Additionally, Vol. 100 of ode describes archery and board game. . The Complete Tang Proses by Dong Gao et al in the Qing Dynasty is considered the most complete collection of literary works of the Tang Dynasty; the Classified Index of Contents of the Complete Tang Proses compiled by Feng Bingwen (a modern scholar) divides the literary works directly related to sports into two categories, i.e. dances and miscellaneous skills. 15 works are related to dance, while 16 works to miscellaneous skills. It is obvious that this book is no more than a collection of some representative works.

Thus it is observed that both traditional classification of poetry and prose of the Tang Dynasty and today's studies on sports literature are lack of integral and systematic contemplation and reflecting toward sports literature of the Tang Dynasty in respect of both the discussion about sports poetry and the study on prose (ode) of sports.
III. STUDIES ON SPORTS LITERATURE OF TANG DYNASTY IN PAPERS PUBLISHED IN THE PAST 30 YEARS.

Research papers specializing in the study on sports literature of the Tang Dynasty showed their initial shape in the 1980s, but no abundant research results have been achieved because of a variety of limiting conditions. The author retrieved merely over 30 papers on sports literature of the Tang Dynasty that roughly fall into studies on sports poetry and on sports prose (ode), where women's sports poetry constitutes a research highlight.

\section{A. Studies on Sports Poetry}

Clearly proposing the concept of sports poetry of the Tang Dynasty and probing into its characteristics and causes is considered an important contribution of studies on sports poetry of the Tang Dynasty in recent years. The representatives of such papers shall include A Study on Characteristics of Sports Poetry of the Tang Dynasty by Huang Meiqiong, the Sports Poetry of the Tang Dynasty Poetic Feature of Sports by Zhao Xiaohua, and A Brief Account of Sports Poetry of the Tang Dynasty by Zhang Baoqiang and Chen Xiaolong. Huang Meiqiong is the first scholar who proposed the concept of Sports Poetry of the Tang Dynasty in her paper.The paper by Zhao Xiaohua revealed the literary and historical values of sports poetry. The paper by Zhang Baoqiang and Chen Xiaolong made rough statistics of the number of sports poems of the Tang Dynasty by statistical method based on the summarization of above-noted research findings.

In addition to overall research, some papers such as the Ball Games in the Complete Tang Poems by Zhao Jialing and the Leisurely Discussion about Poetry of Chinese Chess by He Xixiang present the study on poetry of single sports activity; some papers such as On Bai Juyi's Music \& Dance Poetry and His Aesthetics of Music \& Dance and On the Creative Features of Du Fu's Music \& Dance Poetry by Fu Zhenggu focus on discussion about sports related literary works of well-known composers of poems and proses, suggesting that the music \& dance poems of Bai and Du as great masters of music and dance description are the centralized manifestation of epoch characteristics of dances of the Tang Dynasty.

Benefiting from the open social atmosphere in the Tang Dynasty, a number of research papers presented the study on women's sports activities; the representatives of such papers include the Women's Sports Activities in Works of Poets of the Tang Dynasty by Cheng Yunfeng and Li Yan that gives a description of the prosperity of women's sports in the Tang Dynasty, the aesthetic ideas and mental outlook of women living in that dynasty, and their referential significance for modern women's sports.

\section{B. Studies on Sports Prose (Ode)}

Poetry and prose enjoyed development in parallel in ancient China, but when compared with studies on poetry, prose (ode) research has been a weak link. In a similar manner, less attention has been paid to sports prose (ode) in respect of sports literature of the Tang Dynasty. What is worth admiring is that $\mathrm{Li}$ Guohua translated a series of 
classic sports proses (odes) including the Ode of Female Dancers' Balance on Ball, the Ode of Playing Ball Game at the Station Thermale and the Ode of Tug-of-war etc. in the 1980 s, creating a precedent of the academic circles' study on sports prose (ode) of the Tang Dynasty. The publication of the Interpretation of the Ode of Female Dancers' Balance on Ball sparked a great discussion in the sports circles. [4] The key issue discussed in the translation was the nature of the "ball". Li Guohua and Dou Li argued that the ball game for female dancers was actually women's football game. . Li Guohua believed the Chinese character "ta" could be explained as "kick" in the Interpretation of the Ode of Female Dancers' Balance on Ball and the Interpretation of the Ode of Female Dancers' Balance on Ball - A Discussion with Comrade Zhang Weiyi, while Dou Li agreed with Li Guohua in the Opinions on Objection against the Interpretation of the Ode of Female Dancers' Balance on Ball. At the same time, Zhang Weiyi, Chen Changyi and Weng Shixun argued that the "ball" described here was a wooden ball. Zhang Weiyi argued in his work -Women's Sports Activities in the Tang Dynasty that the ball game here refers to a game in which the player stands on a one to two-feet-high wooden ball with color painting on its surface, rolling the ball with both feet. Moreover, Zhang Weiyi reiterated his views in his work titled Does the Ode of Female Dancers' Balance on Ball Describe Women's Football? In response to Zhang's view, Chen Changyi further affirmed in his work titled The Ball for Female Dancers is not Women's Football that the ball game played by female dancers is not women's football. Based on careful research, Weng Shixun pointed out in his work titled The Corrected Interpretation of the Ode of Female Dancers' Balance on Ball that the "ball" here refers to a wooden ball.[5] Moreover, Weng made a detailed explanation of this ode sentence by sentence. This fargoing academic contention not only discussed about the important issues of sports history, but has also sparked the widespread academic concern about studies on sports prose (ode) of the Tang Dynasty.

\section{ENLIGHTENMENT BY RESEARCH FINDINGS AND RESEARCH SIGNIFICANCE OF SPORTS LITERATURE OF THE TANG DYNASTY.}

It is observed from the time sequencing of above-noted research papers that the development track of studies on sports literature of the Tang Dynasty is roughly as follows: Firstly, concern about sports themes in poetry and prose of the Tang Dynasty; then, exploratory investigation of sports poetry and prose of the Tang Dynasty on a case by case basis; finally, the gradual build-up of independent understanding of this theme. Since the beginning of the $21 \mathrm{st}$ century, research techniques have been subject to continuous progress, and new research techniques from traditional appreciation to quantitative analysis have been promoting the deepening of studies without intermission. The relevant results have been achieved in sorting out subject matters of sports literature of the Tang Dynasty, which could provide more new revelations for studies on traditional sports culture, especially on sports culture of the Tang Dynasty, help find new subjects of studies on sports culture of the Tang
Dynasty, tap new resources, achieve new research findings, and thus realizing the overall improvement of discipline study.

\section{A. Definition of Sports Literature of the Tang Dynasty}

The author argues that studies on sports culture and literature of the Tang Dynasty shall introduce the concept of sports literature of the Tang Dynasty (including sports poetry and sports prose/ode). Sports literatures of the Tang Dynasty include the literary works of the Tang Dynasty on the theme of sports culture or activities which described the sports activities of the Tang Dynasty as aesthetic object and showed sports culture as creative theme.

\section{B. Significance of the Tang Dynasty Sports Literature Research}

Sports literature of the Tang Dynasty as the excellent combination of poetry \& prose and sports culture have unique cultural value. . Mr. Jiang Xingting, a theater historian once said that the most difficult thing to study the history of Chinese traditional opera and sports should be historical materials. Researching ancient sports history has to be based on sound historical materials of sports. Sports activities of the Tang Dynasty were vividly described in the poetry and prose (ode) of that era,which have hugely enriched the historical materials for studies on sports culture of the Tang Dynasty. Great masters of poetry and prose describing sports activities came forth in great number in the Tang Dynasty and had composed a considerable number of sports activity related works. The Complete Tang Poems,the Complete Tang Proses and other great collections of literary works include over 1500 sports poems and more than 1000 sports proses (odes);in addition to traditional kick-ball game, ancient wrestling, swing, boat race, board game, guiding technique (Daoyin) and a variety of weapon-operating skills, the sports events described in such literary works also include a good few of women's sports events such as women's kick-ball game and ancient women's polo. These literary works make up for the lack of original materials of sport in Tang Dynasty and are used with historical materials on a mutual-corroboration basis to have undoubtedly made far reaching contribution to studies on sports culture of the Tang Dynasty and on ancient sports history of China. Since sports literature of the Tang Dynasty is considered a resplendent bright pearl in the vast treasury of literature and arts, the research thereof should naturally constitute the research of characteristics of Chinese traditional sports culture, helping improve the influence of Tang culture and promote the transmission of Chinese traditional culture.

\section{V.CONCLUSION}

In a word, the research of sports literature of the Tang Dynasty has been breaking new ground without intermission in the past few decades, and the innumerable great achievements have laid a good foundation for further research. However, since sports literature of the Tang Dynasty has been remain indifferent too long, both the breadth and depth of current research falls short of our expectation and exhibits various deficiencies from the 
macro-perspective of study subject and higher requirements:

1) Imbalance of research effort: People pay much more attention to poetry than to prose (ode).

2) Lots of superficial researches and repetitive researches presented few original views. It should be particularly noted that excessive attention has been given to some certain sports poems; as a result, the subjects of study were extremely simplex, concentrated or even repeated.

3) Monotonous research techniques lead to obviously inadequate integral and systematic study.

By revealing the existing problems and deficiencies to be urgently solved in research of the sports literature of the Tang Dynasty, this paper is intended to demonstrate there are still enormous research space in respect of sports literature of the Tang Dynasty as a research subject. Integral and systematic concern about studies on sports literature of the Tang Dynasty based on relatively complete materials is the only way to preferably manifest the characteristics of traditional sports culture and carry forward Chinese traditional sports culture. We should make every effort to achieve more fresh and valuable results.

\section{ACKNOWLEDGMENT}

The author gratefully acknowledge the financial support of National Social Science Foundation of China(Grant No.12XZW010), the Ministry of education Humanities and Social Science Foundation of China(11YJC751107) and the Sports Culture Development Center of State Physical Cultural Administration research Foundation of China(2012-2014TYWHY207).

\section{REFERENCES}

[1] Z.X. Zhang, Classified Collection of Tang's Poems, Shanghai: Shanghai Classics Publishing House, 2006, pp. 227-248.

[2] Q.Yan,Tang Poetry and Chang'an, Xi'an: Xi'an Publishing House, 2003, pp. 224-245.

[3] G.H.Li, Highlights of Chinese Classical Sports Literatures, Xi'an: Sanqin Press, 2008.

[4] G.H.Li, "Interpretation of the Ode of Female Dancers' Balance on Ball",Sports World,China, pp. 19-21, June 1983.

[5] S.X.Weng,"The Corrected Interpretation of the Ode of Female Dancers' Balance on Ball” ,Sports Culture Guide,Beijing, pp. 29-33, January 1987. 